\title{
Promotion of Science Communication through Regional Office of Astronomy for Development
}

\section{S. Farmanyan, A. Mickaelian}

Address: Byurakan Astrophysical Observatory, Armenia,

E-mail: sona.farmanyan@mail.ru

\begin{abstract}
The present study is devoted to the introduction of the outreach activities of IAU South West and Central Asia Regional Office of Astronomy for Development (SWCA ROAD) Significant communications gap between scientists and society is rendered. We show how to gain new enthusiasts of the Universe by science popularization. We point out the positive outcome of the science communication such as the rejection of superstitious beliefs, astrology and numerology. We analyze the basic processes of communication that explain how different publics deal with scientific information and we apply these insights so as to help improve communication practices in the field of science. Special focus is given on the science-society relationship and the usage of the persuasive and effective means like science museums, science exhibitions, science festivals, science busking, science cafes and pubs, public lectures, talks and discussions, scientific journalism and scientific tourism. We have implemented some of these in the frame of SWCA ROAD activities; we share our experience. It is worth mentioning that in most of these initiatives, astronomers have taken the leadership as most of the attractive topics in science communication are astronomy and space sciences, extraterrestrials, astrology, cosmic catastrophes, etc. We suggest science communicators to use entertainments including humor, storytelling and metaphors. Science communication may also be realized by websites and social media platforms. We conclude with future tendencies of science communication and benefits of the scientists and young researchers who are actively involved in science outreach activities.
\end{abstract}

Keywords: Science Communication, Science Outreach, Science Popularization, Social Media.

\section{Introduction}

Outreach is the activity of providing popularization services. Our Astronomy outreach activities are targeted to enforce human to space relationship. The science communication that IAU South West and Central Asia Regional Office of Astronomy for Development is doing is more connecting the public to the space than educating them. A key component of outreach is that the groups providing it are not stationary, but mobile; in other words, they are meeting those in need of outreach services at 
the locations where those in need are (Hardy 2010). Science communication looks outside the box to all sorts of people with different backgrounds and perspectives. Rhodes (1996) distinguishes between three types of outreach:

- domiciliary (undertaken at individual homes),

- detached (undertaken in public environments and targeting individuals), and

- peripatetic (undertaken at public or private environments and targeting organizations rather than individuals).

As an academic discipline science communication is a relatively new field, which in the United Kingdom has undergone three main stages (Bauer 2009): Scientific Literacy, Public Understanding of Science (PUS) and Public Engagement with Science and Technology (PEST). Science communication succeeds when the public feels the science as part of their lives.

\section{IAU SWCA ROAD Outreach}

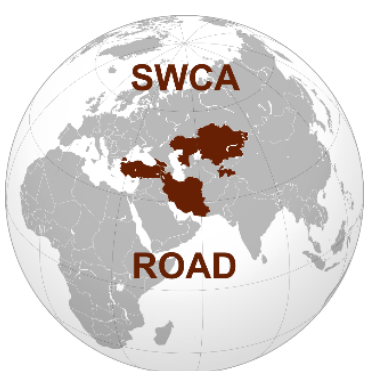

IAU South West and Central Asia Regional Office of Astronomy for Development (SWCA ROAD) acts in 3 task forces; TF1: Universities and Research, TF2: Children and Schools, and TF3: Public Outreach. Through public outreach activities the office aims to make science related topics reachable to non-experts of the field and to use it for their development. For reaching its aim the office focuses on the science-society relationship and the usage of the persuasive and effective means like science museums, science exhibitions, science festivals, public lectures, talks and discussions, scientific journalism and scientific tourism. For this vision the office has tight collaboration of scientists and journalists. Communicating science to the public is increasingly important in the South West and Central Asian Region. However, some scientists do not have the necessary skills and willingness to do effective public communication. By analyzing cultural point of view people living in South West and Central Asia we can say that people are seeking for sensations. Here people are not only interested in scientific knowledge but also new discoveries made by the people from their own nationality, which arises sense of national pride. As Walsh Lynda (2018), states this causes some to worry that the popularizing of science in the public, questioning whether the further popularization of science will cause pressure towards generalization or sensationalism. It is high time that scientists apply scientific thinking to determine how to better communicate their science. Science progresses through experimentation and evidence. 


\subsection{Methods}

In the $21^{\text {st }}$ century Newtons are mostly created due to social media tools. If the scientific institution does not have successful social strategy so their discoveries will be left in the dust. Here we give some social media method and strategy examples for achieving outreach goals in science communication.

One of the most spread tools of increasing science awareness in the public is to follow Reach, Clicks, Engagement and Hashtag performance of social media posts.

Reach: Post reach is the number of unique users who saw your post. How far is your content spreading across social? Is it actually reaching user's feeds?

Clicks: This is the number of clicks on your content, company name or logo. Link clicks are critical toward understanding how users move through your marketing funnel. Tracking clicks per campaign is essential to understand what drives curiosity or encourages people to buy.

Engagement: The total number of social interactions divided by number of impressions. For engagement, it's about seeing who interacted and if it was a good ratio out of your total reach. This sheds light on how well your audience perceives you and their willingness to interact.

Hashtag performance: What were your most used hash tags on your own side? Which hashtags were most associated with your brand? Or what hashtags created the most engagement?

It is also very important to follow the posts of other scientific institutions. Here you will see post break downs of text, images and video to see what your colleagues are doing to drive the most engagement. Once you dig through the competitive analysis, you'll have a better idea of what the public wants.

Every social media campaign maker should have exact goal. And before making social media campaign one should also consider that organization's (scientist) mission and goals. While making social media goals these questions should be answered:

- Who is your target audience?

- What message you want to send your audience?

- How the audience will learn a lesson or benefit from your campaign?

The experience shows that successful social media marketing campaign of science communication may raise science awareness and improve communication and interaction with key audience. Delivering effective science communication can be a time-consuming and resource-draining task, especially if you are having to teach yourself a whole new skill set on top of your other academic commitments. However, 
it is also an extremely rewarding and enjoyable pursuit, which can help to further develop skills that are useful in other areas of academia, such as communication and networking (Illingworth \& Roop 2005).

\subsection{Activities}

Scientific Journalism working group is created for getting science writers and science journalists in Armenia together and share information through social media. According to the statistics, $50-90 \%$ of science publications in mass media somehow relate to space topics: astronomy and astrophysics, space flights, space catastrophes, astrobiology, extraterrestrials, etc. That is why we take an initiative to create such a group and directly circulate information to its members for their further study and publication. In the frame of scientific journalism initiative, a number of press releases are distributed and monthly ArASNews Newsletter is released. Annual science writers' prizes are also given by Armenian Astronomical Society.

SWCA ROAD is developing Scientific Tourism in the region which is aimed at: educating the traveler, promoting public interest to science, providing funds for science heritage conservation ,providing funds for new research projects, directly benefiting the economic development and political empowerment of local communities and fostering respect for different national sciences. Scientific tourism may also significantly contribute to educational level by involving school pupils and students in cognitive tours to research organizations. It also concerns the organization of scientific conferences and other events, as in this case a number of scientists travel to the given country combining science and tourism.

Star Gazing events_are organized under the starry roof of the Universe. The star gazing is accompanied by the talks and explanations of professional astronomers. Both Byurakan Astrophysical Observatory facilities (small telescopes) and other amateur telescopes are involved.

Byurakan Science Camp is for teenagers interested in science. The Science Camp has rather rich program, including Scientific, Educational and Social ones. The Scientific Program includes a number of lectures given on various topics of Astronomy and other fields by BAO scientists, as well as observations and tutorials are organized. The Educational Program includes intellectual games and English lessons. The Social Program includes many excursions, sports games, etc. A number of prizes are given to campers or their active talks and question, intellectual and sport games. 
The Armenian Astronomical Society together with Byurakan Astrophysical Observatory is successfully accomplishing the lecture project "From Space to School". A general presentation on "Wonders of the Universe" (PowerPoint file) is presented in the local schools for 6 years. The presentation includes the information on the history and modern state of Astronomy, it presents developments, achievements of BAO led by the outstanding scientist Viktor Ambartsumian and other famous astrophysicists, and a lot of attractive photos of the Universe.

Astro Clubs at 10 villages. At this project we have trained 20 teachers to use amateur telescopes, Stellarium software and sky map for running Astro Clubs at their villages, for each village there are two teachers. Teachers train young people to use telescopes and give elementary Astronomy knowledge, and after which these young people organize star gazing events for the villagers. During these star gazing events some competitions and games are also organized.

Junior Explorers Clubs are being run at 20 villages and here again like Astro Clubs project we train teachers to make chemical and physical experiments and they pass their skill to school children. Every month these junior explorers organize interactive events for the local people.

Acknowledgments. The authors thank IAU OAD Director Kevin Govender and IAU Office for Astronomy Outreach (OAO) Coordinator Szeleung Cheung for their invaluable contribution to the global Astronomy communication activities.

\section{References}

Hardy, K., Kingston, S., Sanders, T., 2010, Ashgate Publishing, Ltd. p. 77

Rhodes, T., 1996. Outreach Work with Drug Users: Principles and Practice. Council of Europe. p. 25

Walsh, L., 2018. "The Double-Edged Sword of Popularization". Science Communication. SAGE Journals

Bauer, M., 2009. "The Evolution of Public Understanding of Science - Discourse and Comparative Evidence" Sci. Technol. Soc., 14 (2), p. 221

Illingworth, S., Roop, H., 2015. "Developing key skills as a science communicator: case studies of two scientist-led outreach programmers" Geosciences, 5 (1), p. 2 